\title{
TimeFun-InSAR Algorithm to Investigate Physical Changes at Bromo Volcano by Using ALOS/PALSAR Data Sets
}

\author{
A. P. Arbad ${ }^{a, b^{*}}$, W.Takeuchi ${ }^{\mathrm{a}}$ (D) , Y. Aoki ${ }^{\mathrm{C}}$ \\ ${ }^{a}$ Dept. of Geomatics Engineering, Sumatera Institute of Technology, Indonesia \\ ${ }^{b}$ Dept. of Civil Engineering, The University of Tokyo, Japan \\ ${ }^{c}$ Earthquake Research Institute, The University of Tokyo, Japan
}

\section{Article Info:}

Received: 3 December 2017

in revised form: January 2019

Accepted: January 2020

Available Online: 7 July 2020

\section{Keywords:}

Volcano, InSAR, TimeFun

\section{*Corresponding Author} Arliandy Pratama Arbada Dept. of Geomatics Engineering, Sumatera Institute of Technology, Indonesia

Dept. of Civil Engineering, The University of Tokyo, Japan Email: arliandyarbad@gmail.com

\begin{abstract}
Mt. Bromo is geographically located in eastern Java Island at $112^{\circ} 57^{\prime} 30^{\prime \prime}$ longitude and $7^{\circ} 56^{\prime}$ latitude, with a large area of caldera $\sim 10 \mathrm{Km} 2$. The land over the volcano is a perfect area for farming. One of the important factors that affect the level of soil fertility is the most mineral-rich soils. Volcanic activities at Mt. Bromo have been recorded in 1775, characterized by small eruptions with cycles ranging from one to five. Regarding this evidence, we tried to investigate the surface changes over the Mt. Bromo by using Time-Series InSAR with TimeFun algorithm. TimeFun is an extension of $S B A S$ to allow incorporating various functions such as seasonal oscillations, polynomials, and step functions as generally it estimates DEM errors as well and allows missing observation. The maximum allowed baseline value is defined and used to constrain the interferogram pair by selecting the manual after differential InSAR processing in single face working. The proposed analysis is based on 27 SAR data sets acquired by the ALOS/PALSAR sensors during the 2007-2017 time interval. The result shows us deformation occurred up to $\sim 10 \mathrm{~cm}$ at the summit of Mt. Bromo during the eruption period. Time-series monitoring of surface deformation to infer volume changes, geometries, and locations of deformation sources involved in the future eruption.
\end{abstract}

How to cite (APA 6th Style):

Copyright () 2020 GJGP-UNDIP This open access article is distributed under a Creative Commons Attribution (CC-BY-NC-SA) 4.0 International license.

Arbad, A., Takeuchi, W., \& Aoki, Y. (2020). TimeFun-InSAR Algorithm to Investigate Physical Changes at Bromo Volcano by Using ALOS/PALSAR Data Sets. Geoplanning: Journal of Geomatics and Planning, 7(1), 17-24. doi: 10.14710/geoplanning.7.1.17-24

\section{INTRODUCTION}

Satellite remote sensing is one of the primary support tools for disaster management. With respect to free of charge satellite images, all the earth observation data by satellites are greatly desired to be provided at no cost for disaster management, not only in the disaster response phase but also in the mitigation and preparedness phase and recovery phase from the higher standpoint (Kaku, 2019). Satellite remote sensing is largely adopted due to its cost effectiveness, short temporal orbiting and large area of coverage (Bello \& Aina, 2014).

Recent studies utilize geospatial data in the form of satellite imagery in disaster management such as earthquakes (Ramdani et al., 2019), landslides (Rathje \& Franke, 2016), floods (Elkhrachy, 2015), and tsunamis (Chaturvedi et al., 2017). Several studies also highlight the use of satellite imagery during the preparedness and monitoring stages of volcano disaster management (Malley et al., 2014; Pallister et al., 2019; Valade et al., 2019). Volcano disaster mitigation is a priority in Indonesia's national development plan due to the large number of active volcanoes, high frequency of eruptions and dense population within volcanic hazards zones (Andreastuti et al., 2019).

About $13 \%$ of the world's active volcanoes are located in Indonesia. Tectonically, the active volcanoes result from a collision between Indian-Australian, Eurasian, and Philippine Plates (Zaennudin, 2010). Volcanic processes that produce various geological and hydrological hazards (Tilling, 1989) are difficult to 
predict and capable of triggering natural disasters on regional to global scales (Chowdhury et al., 2016). Centre of Volcanology and Geological Hazard Mitigation (CVGHM, 2016) Indonesia recorded tectonic activities of Mt. Bromo, their recorded tectonic activity dominated by continuing tremor vibration with a maximum amplitude which tends to fluctuate. Mount Bromo status is now siaga (level 3 of 4). With the potential to evoke phreatic eruptions and magmatic materials, distribution materials such as ash plumes and pyroclastics fall will occur around the volcano. Many methods have been applied (Hooper et al., 2004; Berardino et al., 2002; Ferretti et al., 1999) for observing and monitoring the land surface of unrest volcano, and these study efforts for establishing a good and reliable system for monitoring and predicting the volcano eruption.

Previous research used conventional algorithms in the form of InSAR and DinSAR (Di Traglia et al., 2018; ElGharbawi \& Tamura, 2014; Sousa et al., 2016, Sousa et al., 2014; Wild et al., 2019). The limitation of these algorithms is the problem of spatial and temporal decorrelation. The TimeFun-InSAR algorithm, which is an extension of SBAS, can show the average velocity of surface deformation according to time series by reducing the problem of the decorrelation.

This study aims to implement the TimeFun-DInSAR algorithm to estimate time-series surface deformation at Mt. Bromo regarding big eruptions in 2011 and 2016. The remote sensing method (Lu et al., 2007 ) is the most commonly rapid assessment unrest volcano technique. Remote sensing has been largely implemented to rapid assess assessment (e.g., Voigt et al., 2011) Haiti earthquake in 2010. In the past decade ago, (Abidin et al., 2004) has published a report on the Bromo volcano's surface deformation as detected by GPS. Previous records indicate that Mt. Bromo is dominated by Strombolian eruptions with relatively mildly explosive ones at discrete. The cycle eruption is 5 years.

\section{DATA AND METHODS}

\subsection{Study Area}

This study took place at Mt. Bromo, East Java. Mt Bromo is important to be the study area because it is the best natural tourist destination in Indonesia. In addition, Mt Bromo has an active mountain character and is one of the volcanic attractions in Indonesia. The detail location was illustrated in Figure 1.

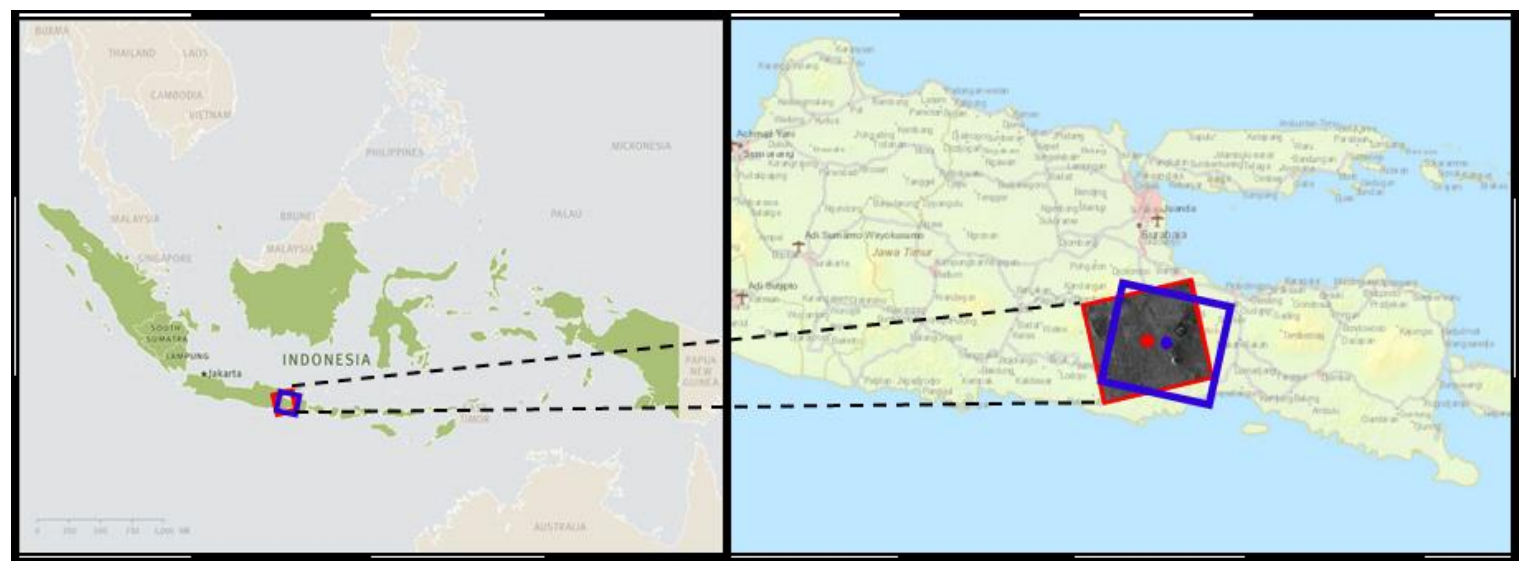

Figure 1. Study area at Mt. Bromo, East Java Province. The red rectangle is identified as ALOS PALSAR ascending orbit direction. The blue rectangle is identified as ALOS PALSAR descending orbit direction.

\subsection{Data}

For analyzing the eruption events in 2011 and 2016, we used SAR data derived from the PALSAR sensor and Images which L-band frequency characteristic onboard from Advanced Land Observing Satellite (ALOS) with active microwave sensor to achieve cloud-free and day-and-night land observation. The dataset is 
composed of 22 SAR images for the 2011 eruption, collected from 24 May 2007 to 4 November 2011 (Descending passes, HH polarization, Track 91, Frame 3780) and 5 SAR images for the 2016 eruption, collected from 11 March 2015 to 03 May 2017 (Descending passes, HH polarization, Track 29, Frame 3780).

\subsection{TimeFun D-InSAR}

Differential InSAR has been exploited to detect ground surface changes (e.g., Arbad et al., 2016) in Mt. Raung, East Java. Despite the fact, Crosetto et al. (2016) has briefly explained of the majority of DInSAR limitations include: (i) the temporal and geometric decorrelations degrade the quality of the interferogram (Hanssen, 2001); (ii) in a noisy interferogram, the unwrapping error could be significant (Ghiglia \& Pritt, 1998); and (iii) atmospheric disturbance can be a significant source of error (Zebker et al., 1997). Several studies (e.g., Zebker et al., 1997; Sandwell \& Price, 1998; Wright et al., 2001) tried to extract deformation by stacking DInSAR images. Time-series analysis of DInSAR images has been invented to overcome some limitations of DInSAR of a single pair. To reduce the fact of limitations, time-series InSAR was applied for filling the gaps of DInSAR (Hetland et al., 2012) has pointed out a new method of time-series observation, TimeFun is an extension of SBAS to allow incorporating various functions, e.g., seasonal oscillations, polynomials, step functions, etc.

The TimeFun method implements the temporal inversion scheme established formerly for multiscale interferometric time-series techniques directly in the data domain. This method explains each pixel's phase evolution using a dictionary of user-defined functions (Agram et al., 2013). For both SBAS and TimeFun analysis, only pixels with a coherence value above a single, user-specified threshold in all interferograms will be selected. Thus, the SBAS algorithm and TimeFun algorithm share the same DS pixels (Gong et al., 2016). The key point of the SBI analysis is to mitigate the impact of decorrelation by properly selecting the interferometric pairs with short temporal (Bt) and geometry (perpendicular) baselines. The maximum allowed baseline value is defined and used to constrain the interferogram pair by selecting the manual after differential InSAR processing in single face working. The observation equation for each pixel was illustrated in eq 1.

$\Phi_{i j}=\sum_{k} \alpha_{k}\left(f^{k}\left(t_{i}\right)-f^{k}\left(t_{j}\right)\right)+e B_{p e r p}^{i j}$ (eq. 1)

Where:

$f^{k}(t)$ : k-th function

$\alpha_{k}$ : Coefficient associated with the k-th function.

In this study, the small baseline interferometric (SBI) method was developed in the StaMPS/MTI toolbox. Three SBI approaches were implemented in the GIAnT toolbox, including SBAS TimeFun analysis.

\section{RESULTS AND DISCUSSION}

This study used full-resolution images without subset. The coherence value ranges from 0 to 1 , where 0 is just noise/less of coherence, indicating the interferometric phase to 1 complete absence of phase noise.

Figure 2 shows the strong correlation among the two-period observations, inside the caldera of Mt. Bromo much more coherence rather than the vegetation area surrounding the Mt. Bromo itself. This could be happened due to less coherence of each image due to the high vegetation. The selection of coherence images should be made carefully, created from stack processing to get the better result of time-series InSAR result. Mt. Bromo's main characteristic displacement is the uplift that occurred in the northeast part of TNBTS caldera with a relative velocity of about $0.16 \mathrm{~cm} / \mathrm{yr}$. The TimeFun Interferometric processing will 
give a deformation field from which we can infer volume changes, geometries, and locations of the deformation source involved in the eruption. Given previously periodical ground deformation in the caldera of TNBTS before the eruptions have been shown in Figure 3.
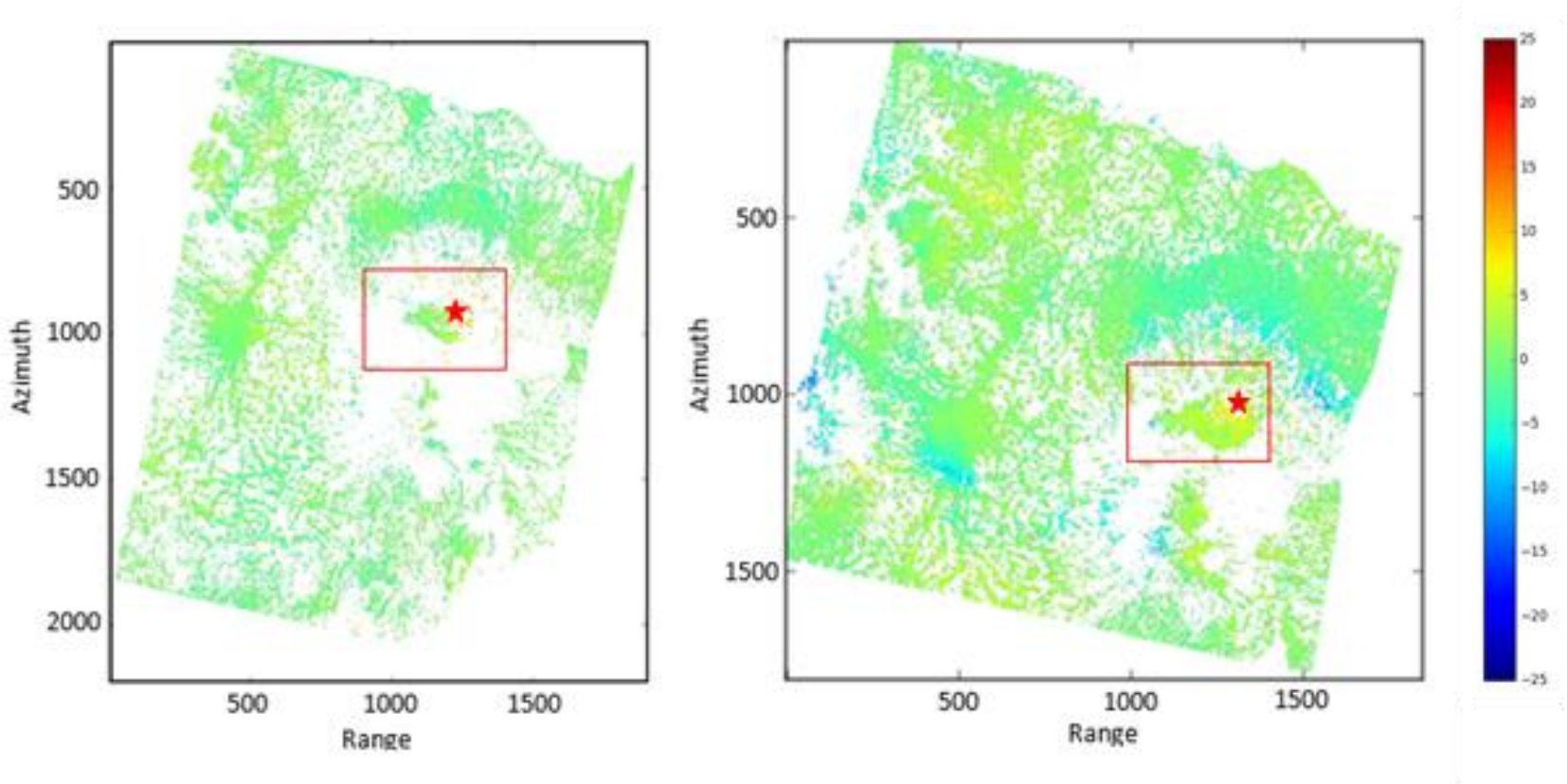

Figure 2. Time-series displacement results of Mt. Bromo for observations 2007-2011 (a) and 2014-2017 (b) with the color range unit in centimeters. The red rectangle is the area over Mt. Bromo Indonesia

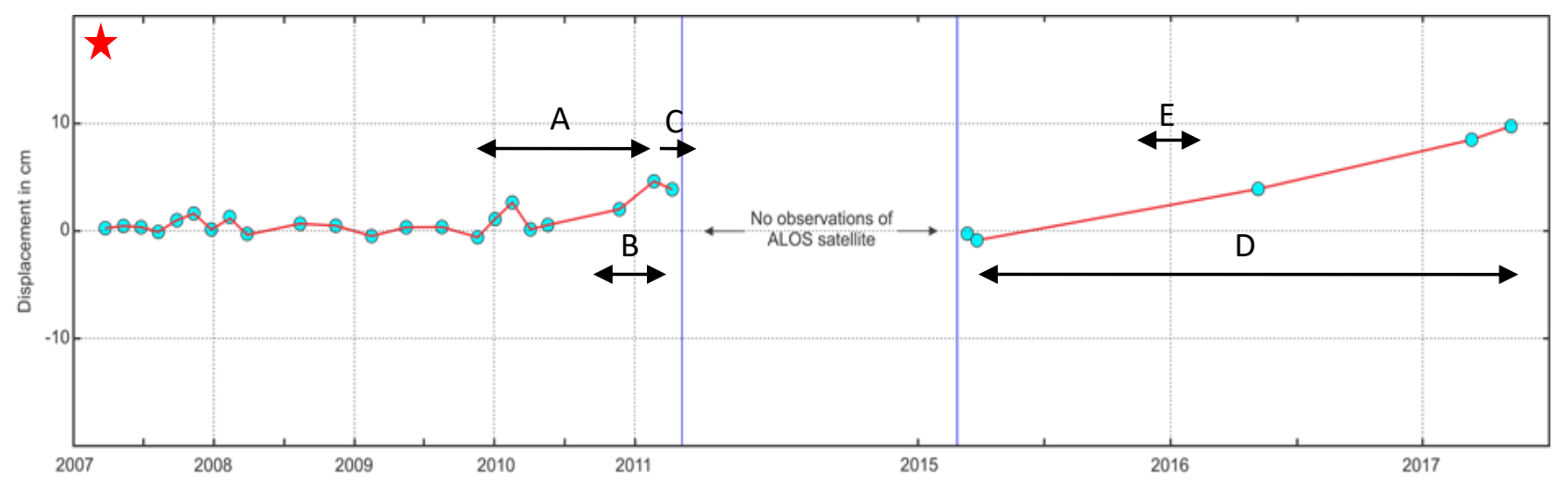

Figure 3. Time-series displacement results inside Mt. Bromo's caldera based on the TimeFun InSAR method obtained from March 2007 to May 2017. The displacement unit is in centimeters with a negative value represent the subsidence and a positive value represent the uplift.

The graph showed clearly the displacement that happened over Mt. Bromo. In our observation at Mt. Bromo, the surface at Mt. Bromo is shown instability since March 2007, which represented by the point in a graph. In the late of 2009 to Feb 2011, Mt. Bromo ran into inflation (see arrow A), and started eruption in the late of 2010 to Feb/March 2011, represented by arrow B. In the last of observations in the 2011 eruption, Mt. Bromo's surface slightly deflated (arrow C) where Mt. Bromo's activity is getting decrease. It seems abnormal that it may be caused systematically by an inappropriate selection of the reference points. In the 2016 eruption, we found the surface of Mt. Bromo is dramatically uplift from March 2015 to May 2017. 
The uplift value in the 2011 and 2016 eruption is nearly similar reach up to $5 \mathrm{~cm}$ but, at the end of the observations, the uplift occurred about $10 \mathrm{~cm}$. This is two times bigger than the 2011 eruption or 2016 eruption. We can assume for the next eruption in 2020 (regarding the 5-year cycle of the eruption Mt. Bromo) is bigger than the 2011 and 2016 eruption. In the arrow D, the inflation is extremely increased at Mt. Bromo from March 2015 to May 2017. Surface deformation of a volcano is controlled by the shape and size of the source, the increment of pressure, and the medium's elastic, viscoelastic, and plastic properties. We present co-eruptive InSAR observations of the recent eruption at Mount Bromo. Moreover, we have to break the gaps of loss observation within the ALOS satellite's two-period observations. It could be opened the future research challenges, extracting the missing value to understand mechanisms behind the volcano cycle, particularly Mt. Bromo.
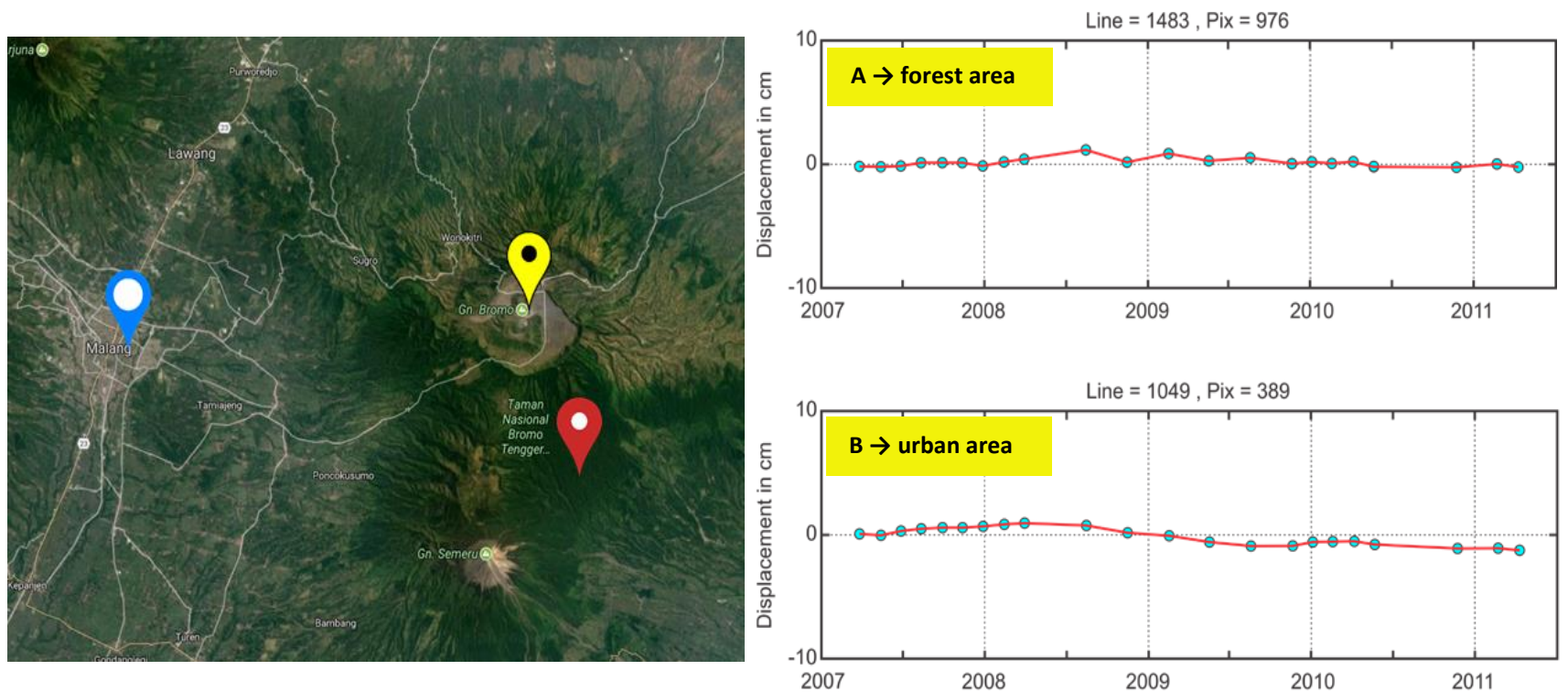

Figure 4. Time-series displacement graphs of forest area (Figure A) and urban area (Figure B). The displacement unit is in centimeters with a negative value represent the subsidence and a positive value represents the uplift.

Regarding the TimeFun method, we also plotted the displacement graph in some sample areas such as urban areas and forest areas. We wanted to know about the displacement except for the main target. We selected point A in the forest area inside the National Park of Bromo Tengger Semeru. The graph shows the ground surface is relatively stable. It shows uplift. It may be caused by the forest ecosystem cycle like fallen trees. In the urban area (Figure 4b), we selected the sample point in Malang city. Malang is one of the most populated cities in East Java Province. The graph shows the subsidence has occurred in Malang city. Subsidence in the urban area may be caused by groundwater and gas extraction (e.g., Chaussard et al., 2013 and Chen et al., 2003) or due to the flood. The study area's images are composed of complex land cover types. Our pre-study of interferometric processing expected the urban areas and areas with exposed rocks/sandy to maintain. Such as the mount Bromo area is a high level of coherence even after several years of observation.

The ALOS/PALSAR images have the highest resolution to investigate the surface's features and deformation over Mt. Bromo. The capabilities of remote sensing could be appreciated for active volcano monitoring. However, the remote sensing method still has limitations. We need the in situ measurement to validate the result of surface displacement (TimeFun method) over Mount Bromo. For future work, we can use this result. This is a good agreement with geological assessment for the human assessing in risk and vulnerability frame to create the mitigation plan based on the geographic information system analysis. 


\section{CONCLUSION}

In this study, we have presented the TimeFun Differential InSAR method to get the time-series land surface deformation over the Mt. Bromo to understand the annual growing characteristics of deformation under the high-intensity of volcanic activity of Mt. Bromo Indonesia and recognize the ground deformation features. We found the uplift evidence based on the TimeFun analysis result up to $5 \mathrm{~cm}$ in November 2010, continuing to February 2011, and slightly uplift until the end of the observations. Nearly two times the uplift occurred at the caldera of Mt. Bromo. Another error could be happened, which may be caused systematically by an inappropriate selection of the reference points or another volcanic activities phenomenon such as the ash-materials. The present study has focused on the characteristics of the TimeFun methods and our data processing experience to benefit future users of these modules.

\section{ACKNOWLEDGMENTS}

Thanks to JAXA (Japan Aerospace Exploration Agency) to provide PALSAR/PALSAR-2 images. Remote Sensing of Environment and Disaster Laboratory, Industrial Institute of the Technology University of Tokyo. LPDP (Indonesia Endowment Fund For Education) Scholarship, Indonesia Ministry of Finance, and Earthquake Research Institute share knowledge on volcano sight.

\section{REFERENCES}

Agram, P. S., Jolivet, R., Riel, B., Lin, Y. N., Simons, M., Hetland, E., ... Lasserre, C. (2013). New radar interferometric time series analysis toolbox released. Eos, Transactions American Geophysical Union, 94(7), 69-70. [Crossref]

Abidin, H. Z., Andreas, H., Gamal, M., Hendrasto, M., Suganda, O. K., Purbawinata, M. A., ... others. (2004). The deformation of Bromo Volcano (Indonesia) as detected by GPS surveys method. Positioning, 1(8).

Andreastuti, S., Paripurno, E. T., Gunawan, H., Budianto, A., Syahbana, D., \& Pallister, J. (2019). Character of community response to volcanic crises at Sinabung and Kelud volcanoes. Journal of Volcanology and Geothermal Research, 382, 298-310. [Crossref]

Arbad, A. P., Takeuchi, W., Ardy, A., \& Ashari, R. A. (2016). Observing Deformation at Mt. Raung East Java Based on PALSAR-2 Imagery by Using Interferometric SAR. IOP Conference Series: Earth and Environmental Science, 47(1), 12021. [Crossref]

Bello, O. M., \& Aina, Y. A. (2014). Satellite Remote Sensing as a Tool in Disaster Management and Sustainable Development: Towards a Synergistic Approach. Procedia - Social and Behavioral Sciences, 120, 365-373. [Crossref]

Berardino, P., Fornaro, G., Lanari, R., \& Sansosti, E. (2002). A new algorithm for surface deformation monitoring based on small baseline differential SAR interferograms. IEEE Transactions on Geoscience and Remote Sensing, 40(11), 2375-2383. [Crossref]

Chaturvedi, S. K., Srivastava, P. K., \& Guven, U. (2017). A brief review on tsunami early warning detection using BPR approach and post analysis by SAR satellite dataset. Journal of Ocean Engineering and Science, 2(2), 83-89. [Crossref]

Chaussard, E., Amelung, F., Abidin, H., \& Hong, S.-H. (2013). Sinking cities in Indonesia: ALOS PALSAR detects rapid subsidence due to groundwater and gas extraction. Remote Sensing of Environment, 128, 150-161. [Crossref]

Chen, C., Pei, S., \& Jiao, J. (2003). Land subsidence caused by groundwater exploitation in Suzhou City, China. Hydrogeology Journal, 11(2), 275-287. [Crossref]

Chowdhury, T. A., Minet, C., \& Fritz, T. (2016). A prototype of an automated high resolution InSAR volcanomonitoring system in the MED-SUV project. EGUGA, EPSC2016--13177.

Crosetto, M., Monserrat, O., Cuevas-González, M., Devanthéry, N., \& Crippa, B. (2016). Persistent scatterer interferometry: A review. ISPRS Journal of Photogrammetry and Remote Sensing, 115, 78-89.

Di Traglia, F., Nolesini, T., Ciampalini, A., Solari, L., Frodella, W., Bellotti, F., ... Casagli, N. (2018). Tracking morphological changes and slope instability using spaceborne and ground-based SAR data. Geomorphology, 300, 95-112. [Crossref] 
ElGharbawi, T., \& Tamura, M. (2014). Measuring deformations using SAR interferometry and GPS observables with geodetic accuracy: Application to Tokyo, Japan. ISPRS Journal of Photogrammetry and Remote Sensing, 88, 156-165. [Crossref]

Elkhrachy, I. (2015). Flash Flood Hazard Mapping Using Satellite Images and GIS Tools: A case study of Najran City, Kingdom of Saudi Arabia (KSA). Egyptian Journal of Remote Sensing and Space Science, 18(2), 261-278. [Crossref]

Ferretti, A., Prati, C., \& Rocca, F. (1999). Multibaseline InSAR DEM reconstruction: The wavelet approach. IEEE Transactions on Geoscience and Remote Sensing, 37(2), 705-715. [Crossref]

Ghiglia, D. C., \& Pritt, M. D. (1998). Theory, Algorithms, and Software. New York, USA: A Wiley-Interscience Publication.

Gong, W., Thiele, A., Hinz, S., Meyer, F. J., Hooper, A., \& Agram, P. S. (2016). Comparison of small baseline Interferometric SAR processors for estimating ground deformation. Remote Sensing, 8(4), 330. [Crossref]

Hanssen, R. F. (2001). Radar interferometry: data interpretation and error analysis (Vol. 2). Springer Science \& Business Media. [Crossref]

Hetland, E. A., Musé, P., Simons, M., Lin, Y. N., Agram, P. S., \& DiCaprio, C. J. (2012). Multiscale InSAR time series (MInTS) analysis of surface deformation. Journal of Geophysical Research: Solid Earth, 117(B2). [Crossref]

Hooper, A., Zebker, H., Segall, P., \& Kampes, B. (2004). A new method for measuring deformation on volcanoes and other natural terrains using InSAR persistent scatterers. Geophysical Research Letters, 31(23). [Crossref]

Kaku, K. (2019). Satellite remote sensing for disaster management support: A holistic and staged approach based on case studies in Sentinel Asia. International Journal of Disaster Risk Reduction, 33(October 2018), 417-432. [Crossref]

Lu, Z., Kwoun, O., \& Rykhus, R. (2007). Interferometric synthetic aperture radar (InSAR): its past, present and future. Photogrammetric Engineering and Remote Sensing, 73(3), 217. [Crossref]

Malley, R. T. O., Behrenfeld, M. J., Westberry, T. K., Milligan, A. J., Reese, D. C., \& Halsey, K. H. (2014). Improbability mapping: A metric for satellite-detection of submarine volcanic eruptions. Remote Sensing of Environment, 140, 596-603. [Crossref]

Pallister, J., Wessels, R., Griswold, J., Mccausland, W., Kartadinata, N., Gunawan, H., ... Primulyana, S. (2019). Monitoring, forecasting collapse events, and mapping pyroclastic deposits at Sinabung volcano with satellite imagery Sinabung Toba Caldera. Journal of Volcanology and Geothermal Research, 382, 149-163. [Crossref]

Ramdani, F., Setiani, P., \& Setiawati, D. A. (2019). Analysis of sequence earthquake of Lombok Island, Indonesia. Progress in Disaster Science, 4, 100046. [Crossref]

Rathje, E. M., \& Franke, K. (2016). Remote sensing for geotechnical earthquake reconnaissance. Soil Dynamics and Earthquake Engineering, 91, 304-316. [Crossref]

Sandwell, D. T., \& Price, E. J. (1998). Phase gradient approach to stacking interferograms. Journal of Geophysical Research: Solid Earth, 103(B12), 30183-30204. [Crossref]

Sousa, J. J., Ruiz, A. M., Bakoň, M., Lazecky, M., Hlaváčová, I., Patrício, G., ... Perissin, D. (2016). Potential of C-Band SAR Interferometry for Dam Monitoring. Procedia Computer Science, 100, 1103-1114. [Crossref]

Sousa, J. J., Ruiz, A. M., Hooper, A. J., Hanssen, R. F., Perski, Z., Bastos, L. C., ... Avilés, M. (2014). Multitemporal InSAR for Deformation Monitoring of the Granada and Padul Faults and the Surrounding Area (Betic Cordillera, Southern Spain). Procedia Technology, 16, 886-896. [Crossref]

Tilling, R. I. (1989). Volcanic hazards and their mitigation: progress and problems. Reviews of Geophysics, 27(2), 237-269. [Crossref]

Valade, S., Ley, A., Massimetti, F., Hondt, O. D., Laiolo, M., Coppola, D., ... Walter, T. R. (2019). Multisensor Sentinel Missions and Artificial Intelligence : The MOUNTS Monitoring System. 1-31.

Voigt, S., Schneiderhan, T., Twele, A., Gähler, M., Stein, E., \& Mehl, H. (2011). Rapid damage assessment and situation mapping: learning from the 2010 Haiti earthquake. Photogrammetric Engineering and Remote Sensing (PE\&RS), 77(9), 923-931. [Crossref]

Wild, C. C., Marsh, O. O., \& Rack, W. (2019). Differential interferometric synthetic aperture radar for tide modelling in Antarctic ice-shelf grounding zones. Cryosphere, 13(12), 3171-3191. [Crossref] 
Wright, T., Parsons, B., \& Fielding, E. (2001). Measurement of interseismic strain accumulation across the North Anatolian Fault by satellite radar interferometry. Geophysical Research Letters, 28(10), 21172120. [Crossref]

Zaennudin, A. (2010). The characteristic of eruption of Indonesian active volcanoes in the last four decades. Jurnal Lingkungan Dan Bencana Geologi, 1(2), 113-129.

Zebker, H. A., Rosen, P. A., \& Hensley, S. (1997). Atmospheric effects in interferometric synthetic aperture radar surface deformation and topographic maps. Journal of Geophysical Research: Solid Earth, 102(B4), 7547-7563. [Crossref] 